CLINICAL REPORT

\author{
A. Förster \\ A. Gass \\ R. Kern \\ M.E. Wolf \\ M.G. Hennerici \\ K. Szabo
}

\section{MR Imaging-Guided Intravenous Thrombolysis in Posterior Cerebral Artery Stroke}

SUMMARY: PCA stroke was under-represented in or excluded from the clinical trials examining thrombolysis based on the PWI-DWI mismatch concept. We present 6 patients with PCA stroke treated with thrombolysis in an extended time window by using MR imaging criteria. Symptoms included aphasia, sensorimotor hemiparesis, hemineglect, and homonymous hemianopia. Initial MR imaging demonstrated circumscribed ischemic lesions in the thalamus or hippocampus; MR angiography showed PCA occlusion with corresponding hypoperfusion. Follow-up MR imaging showed partial/complete recanalization in 4 patients with minor infarction growth, while in 1 patient, PCA occlusion persisted, resulting in a large PCA infarction. Three patients improved within 2 hours; at discharge, homonymous hemianopia had resolved in 3 patients. At 3-month follow-up, 4 patients had an mRS score of 0 or 1 . These results support the approach to treat patients with PCA stroke with thrombolysis based on the mismatch concept. Because rehabilitation options for hemianopia are limited, thrombolysis may enhance the chance of a favorable outcome.
$\mathbf{P}$ osterior circulation stroke accounts for approximately $15 \%$ of all acute ischemic strokes and may cause permanent hemianopia, hemiparesis, or neuropsychological deficits, which may result in considerable permanent disability. ${ }^{1} \mathrm{Nev}-$ ertheless, the large clinical trials investigating acute therapy with rtPA in acute ischemic stroke focused on anterior circulation stroke or even excluded patients with posterior circulation stroke from participation. ${ }^{2-4}$ The same holds true for clinical trials examining MR imaging - guided thrombolysis based on the PWI-DWI mismatch concept. ${ }^{5,6}$ We report a case series of 6 patients with acute ischemic stroke in the PCA territory treated with intravenous thrombolysis in an extended time window based on the DWI-PWI-mismatch concept.

\section{Materials and Methods}

From a prospectively collected stroke unit registry, we identified 5948 patients with acute ischemic stroke admitted between January 2004 and December 2009. Altogether, 818 (13.8\%) patients were treated with rtPA; among these, $71(8.7 \%)$ patients received intravenous thrombolysis $(0.9-\mathrm{mg} / \mathrm{kg} \mathrm{rtPA}$; maximum, $90 \mathrm{mg}$; with $10 \%$ of the dose given as a bolus followed by an infusion lasting 60 minutes) in an extended time window guided by acute stroke MR imaging based on the DWI-PWI mismatch concept. Treatment was performed on an individual off-label-use basis with patient informed consent documented according to ethics committee approval. Six of the $71(8.5 \%)$ patients had acute ischemic stroke in the PCA territory. All clinical data and technical investigations were collected and documented according to a standardized acute stroke care protocol.

Initial and follow-up MR imaging was performed on a $1.5 \mathrm{~T}$ sys-

Received June 26, 2010; accepted after revision July 22.

From the Department of Neurology, Universitäts Medizin, University of Heidelberg, Mannheim, Germany.

Please address correspondence to Alex Förster, MD, Department of Neurology, Universitäts Medizin, Theodor-Kutzer-Ufer, 68137 Mannheim, Germany, e-mail: foerster@neuro.ma. uni-heidelberg.de

DOI 10.3174/ajnr.A2300 tem (Magnetom Sonata; Siemens, Erlangen, Germany). A standardized protocol was used in all patients: 1) transverse, coronal, and sagittal localizing sequences followed by transverse oblique contiguous images aligned with the inferior borders of the corpus callosum (applied on sequences 2-6), 2) T2-weighted images, 3) T1-weighted images, 4) DWI, 5) FLAIR, and 6) PWI following the first pass of contrast bolus through the brain (20-mL gadoterate meglumine, Dotarem; Guerbet, Aulney-sous-Bois, France) injected manually through a large-gauge venous cannula into the antecubital vein; and 7) 3D time-of-flight MRA sequences of the circle of Willis and the neck arteries in the coronal direction.

The size of the acute ischemic lesion was measured on DWI. The size of perfusion deficit was measured on TTP maps by manually delineating the region of interest with commercially available image analysis software, nordicICE (Nordic Imaging Lab, Bergen, Norway). Probable stroke cause was classified according to the A-S-C-O (phenotypic) classification of stroke described recently. ${ }^{7}$

\section{Results}

The Table shows the baseline and MR imaging characteristics of the 6 patients ( 4 men, 2 women). On initial DWI, 1 patient had thalamic infarction (patient 2), while in the other 5 cases, the hippocampus was affected. MRA showed occlusion of the right or left PCA and correspondingly hypoperfusion in the right or left PCA territory (Fig 1). The time from symptom onset to treatment varied from 185 to 390 minutes.

Four patients improved significantly within 2 hours after therapy, and at discharge, homonymous hemianopia had resolved completely in 3 patients (patients 3, 4, and 6). The condition of patient 5 deteriorated with conjugate horizontal gaze palsy and right sensorimotor hemiparesis. In patient 2 , neither significant improvement nor deterioration of clinical symptoms was observed. Follow-up MR imaging was performed after 1-6 days and showed complete or partial recanalization in 4 patients. DWI demonstrated acute ischemic stroke in the thalamus only in patient 2 ; in the thalamus and hippocampus 


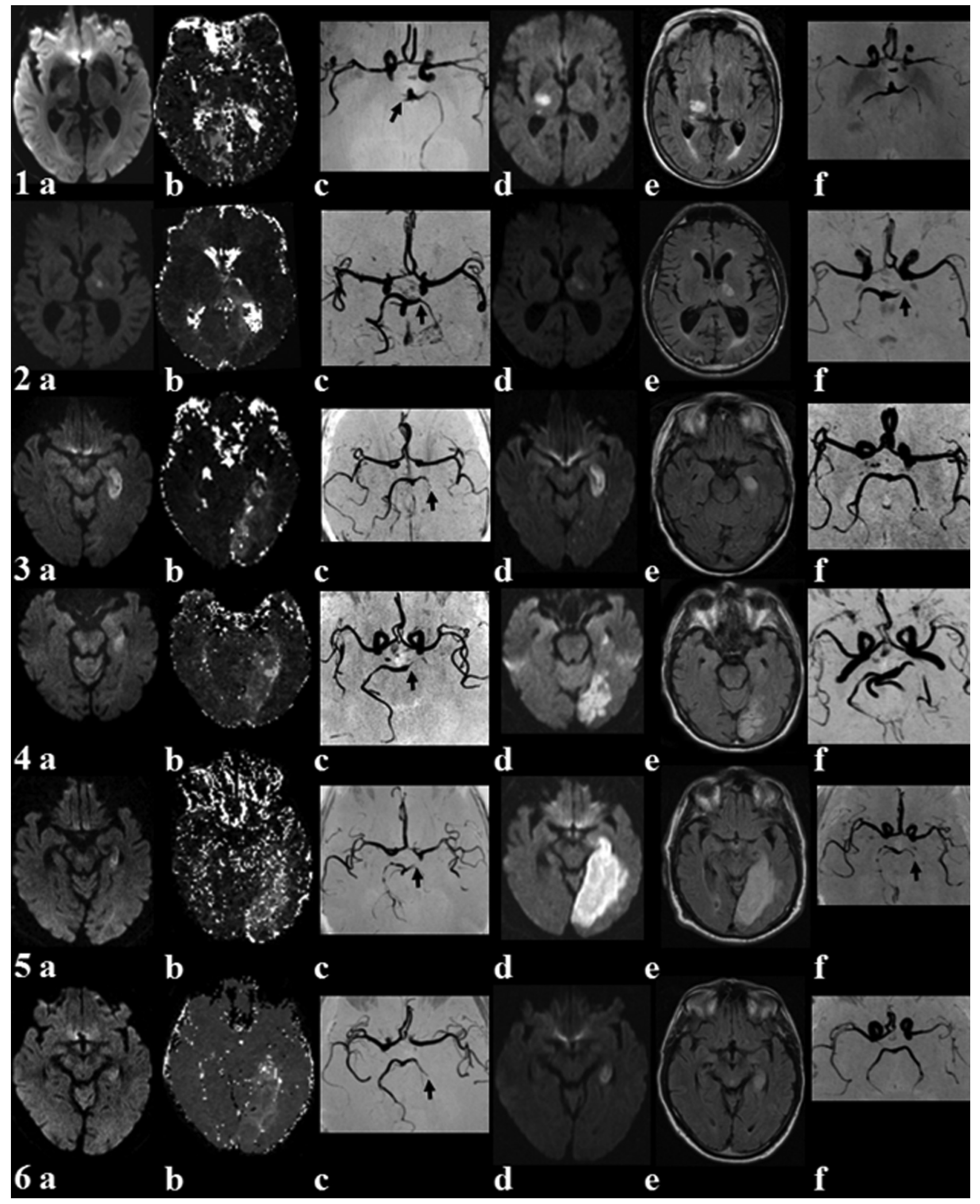

Fig 1. MR imaging in posterior circulation stroke before $(a-c)$ and after $(d-f)$ intravenous thrombolysis. Initial MR imaging shows the ischemic lesion on DWI (a), hypoperfusion on PW (TTP map) (b), and vessel pathology (black arrow) on MRA (c). Follow-up MR imaging lesion on DWI ( $d$ ) and T2 FLAIR imaging (e), as well as recanalization or persistent vessel pathology (black arrow) on MRA (f).

in patients 1 and 6; in the thalamus, hippocampus, and occipital lobe in patient 3; and in the thalamus, hippocampus, splenium, and occipital lobe in patient 4 . A remarkable growth of infarct size was detected in patient 5, with nearly complete PCA territory infarction and persisting PCA occlusion.

At 3-month follow-up 4 patients had an mRS score of 0 or 
Baseline data, clinical outcome, A-S-C-O subtype, and MR imaging characteristics

\begin{tabular}{|c|c|c|c|c|c|c|c|c|c|}
\hline No. & $\begin{array}{l}\text { Age } \\
\text { (yr) }\end{array}$ & Symptoms & $\begin{array}{c}\text { NIHSS } \\
\text { Day 1/ } \\
\text { Discharge }\end{array}$ & $\begin{array}{c}\mathrm{mRS} \\
\text { Day } \\
90\end{array}$ & $\begin{array}{c}\text { OTT } \\
(\min )\end{array}$ & $\begin{array}{l}\text { A-S-C-O } \\
\text { Subtype }\end{array}$ & $\begin{array}{c}\text { Before rtPA } \\
\text { DWl/PWI, } \\
\text { Volume } \\
\left(\mathrm{cm}^{3}\right)\end{array}$ & $\begin{array}{c}\text { After rtPA } \\
\text { DWl, } \\
\text { Volume } \\
\left(\mathrm{cm}^{3}\right)\end{array}$ & Follow-Up MRA \\
\hline 1 & 85 & $\begin{array}{l}\text { Homonymous hemianopia, } \\
\text { sensorimotor hemiparesis }\end{array}$ & $5 / 4$ & 3 & 375 & A3S3C100 & $0.9 / 33.1$ & 6.2 & Partial recanalization \\
\hline 2 & 77 & Aphasia, facial palsy & $2 / 2$ & 1 & 195 & A3S3C000 & $1 / 24.7$ & 1 & No recanalization \\
\hline 3 & 70 & $\begin{array}{l}\text { Aphasia, homonymous hemianopia, } \\
\text { sensorimotor hemiparesis }\end{array}$ & $6 / 1$ & 0 & 300 & A3S3C000 & $3.2 / 38.8$ & 7 & Partial recanalization \\
\hline 4 & 68 & $\begin{array}{l}\text { Homonymous hemianopia, } \\
\text { sensorimotor hemiparesis }\end{array}$ & $5 / 1$ & 0 & 285 & A3S3C100 & $3.6 / 53$ & 18.5 & Partial recanalization \\
\hline 5 & 83 & $\begin{array}{l}\text { Homonymous hemianopia, } \\
\text { hemihypesthesia }\end{array}$ & $3 / 12$ & 5 & 380 & A3S3C000 & $1.6 / 37.8$ & 108 & No recanalization \\
\hline 6 & 67 & $\begin{array}{l}\text { Homonymous hemianopia, } \\
\text { hemihypesthesia, hemineglect }\end{array}$ & $5 / 0$ & 0 & 380 & A3S3C000 & $3.2 / 36.5$ & 5.8 & Recanalization \\
\hline
\end{tabular}

1, 1 patient had an $\mathrm{mRS}$ score of 3 , and 1 patient had an mRS score of 5. Only 1 minor complication (gum bleeding) occurred after thrombolysis.

\section{Discussion}

Due to strict study protocols focusing on anterior circulation stroke-mostly in the middle cerebral artery territory-there are limited data on thrombolysis in PCA stroke. PCA ischemia may present with a nondebilitating neurologic syndrome. Consequently patients might take longer to consult a physician, who in turn might hesitate to recommend thrombolysis, especially because PCA stroke symptoms are not well represented by the NIHSS. ${ }^{8}$ However, because rehabilitation options for visual field defects are limited, ${ }^{9}$ acute PCA stroke should be treated with the same regimen and emphasis as anterior circulation stroke.

We demonstrated that MR imaging identifies constellations in PCA stroke very comparable with those in anterior circulation stroke. A mismatch between an early DWI and PWI lesion can be seen, and the DWI lesion may increase in size (patient 5) unless early recanalization is achieved (patients $1,3,4$, and 6). Natural history studies of PCA stroke indicate that tissue vulnerability and the treatment window in the PCA territory are comparable with anterior circulation stroke and that early recanalization may facilitate a good outcome. MR imaging, including MRA, DWI, and PWI, provides a diagnosis of the vascular lesion and perfusion deficit, which allows estimating the risk for growth of an ischemic lesion.

\section{References}

1. Ng YS, Stein J, Salles SS, et al. Clinical characteristics and rehabilitation outcomes of patients with posterior cerebral artery stroke. Arch Phys Med Rehabil 2005;86:2138-43

2. De Keyser J, Gdovinova Z, Uyttenboogaart M, et al. Intravenous alteplase for stroke: beyond the guidelines and in particular clinical situations. Stroke 2007; 38:2612-18. Epub 2007 Jul 26

3. Hacke W, Kaste M, Fieschi C, et al. Intravenous thrombolysis with recombinant tissue plasminogen activator for acute hemispheric stroke: the European Cooperative Acute Stroke Study (ECASS). JAMA 1995;274:1017-25

4. Hacke W, Kaste M, Fieschi C, et al. Randomised double-blind placebo-controlled trial of thrombolytic therapy with intravenous alteplase in acute ischaemic stroke (ECASS II): Second European-Australasian Acute Stroke Study Investigators. Lancet 1998;352:1245-51

5. Röther J, Schellinger PD, Gass A, et al. Effect of intravenous thrombolysis on MRI parameters and functional outcome in acute stroke $<6$ hours. Stroke 2002;33:2438-45

6. Albers GW, Thijs VN, Wechsler L, et al, for the DEFUSE Investigators. Magnetic resonance imaging profiles predict clinical response to early reperfusion: the diffusion and perfusion imaging evaluation for understanding stroke evolution (DEFUSE) study. Ann Neurol 2006;60:508-17

7. Amarenco P, Bogousslavsky J, Caplan LR, et al. New approach to stroke subtyping: the A-S-C-O (phenotypic) classification of stroke. Cerebrovasc Dis 2009;27:502-08

8. Sato S, Toyoda K, Uehara T, et al. Baseline NIH Stroke Scale score predicting outcome in anterior and posterior circulation strokes. Neurology 2008;70(24 pt 2):2371-77. Epub 2008 Apr 23

9. Schofield TM, Leff AP. Rehabilitation of hemianopia. Curr Opin Neurol 2009; 22:36-40 